\title{
Model of Integrated Estimation of Audit Risk
}

\section{Sergey Arzhenovskiy}

\author{
Andrey Bakhteev \\ Rostov State Economics University (RINH) \\ Email: sarzhenov@gmail.com, a_bakhteev@mail.ru
}

\section{Doi:10.5901/mjss.2015.v6n3s6p241}

\section{Abstract}

Purpose. This paper goes into detail on the advantages of a risk-based approach to auditing financial statements. Methodology. The authors propose a model of the risk estimation process during an audit, taking into account limitations, and put forth the rationale for developing a model of combined risk estimation during audit proceedings, a description of the methodological foundations of the process, a description of the methodological tools applied. Findings. The authors propose the procedure for estimating the risk of deliberate considerable falsification of accounting reporting. Originality. The model of combined risk estimation during audit proceedings is original. In our opinion, the application of a formal methodological instrument will reap the following benefits: simplification of the procedure of collecting information concerning risks within the audit group before discussing the list of identified risk factors; reduced effort required to identify risks; increased audit efficiency, performed on the basis of the risk-oriented approach; coverage of all features confirming the risk of considerable falsification of accounting reporting; a greater level of preparedness among the audit group to discuss considerable falsification risk factors affecting accounting reporting undergoing audit proceedings.

Keywords: audit; method of risk estimation; fraud risk; deliberate considerable falsification of accounting reporting.

\section{Introduction}

One of the key processes that characterises modern-day global economic development is the increased symmetry in reporting of information on the results of the activities of joint-stock companies (JSCS), involving the funds of an unlimited number of people. The aim of this process is to increase the awareness of the average informed user up to a level that enables him/her to make reasonable investment decisions on the basis of annual accounting reporting. Audit companies play a vital role in reducing the risk to the user, as they are responsible for analysing and confirming the authenticity of this reporting. However, since the early $21^{\text {st }}$ century the audit profession has seen a considerable decline in prestige, with public trust in auditors having been damaged for a number of reasons, in particular:

- widespread bankruptcies among major corporations in the U.S. and Europe in the late $20^{\text {th }}$ and early $21^{\text {st }}$ centuries (e.g. Finance director, 2014; Roche-Duffay, 2014) shortly after the issue of audit reports formulated on the basis of continuity assumptions and confirming the authenticity of these corporations' accounting reporting.

- cases in which the management of major JSCs have "bought" auditors' silence regarding losses suffered in the course of their economic activities.

- the process of increasing the transparency of accounting reporting, aimed at satisfying the increasing requirements in regard of their quality, combined with the unwillingness of the management of public companies to notify users of all of the details and risks inherent in their activities.

- inherent difficulty of detecting, using traditional approaches applied within the audit process, where accounting reporting has been falsified as a result of fraudulent actions on the part of management (e.g. Dodge, 1990).

Therefore, the most important and urgent task facing auditors is to develop new methods for estimating the risk of considerable falsification of accounting reporting arising from the fraudulent actions on the part of management in issuing the reporting.

\section{Methodology}

The risk-oriented approach currently applied when rendering audit services is the most progressive in existence, as it is uniquely linked to the expression of confidence. This helps overcome the constraints that are characteristic of the system- 
oriented and verification approaches. R. Dodge (1990) describes in great detail the peculiarities of the verification, system-oriented and risk-oriented approaches within the framework of the audit process and its requirements. It is clear that the main disadvantage of the verification approach is the fact that it cannot be applied outside the accounting system of the entity undergoing audit proceedings. Therefore, a verification audit is unable to detect most transactions that are not reflected in the entity's accounting registers. The essence, and indeed, the main advantage, of the risk-oriented approach is that its application makes it possible to identify the factors that determine the level of risk of considerable falsification of accounting reporting at the highest level of the entity's management. In this case, the attention of the auditor is focused on searching for factors that attest to the existence of probable actions undertaken by the entity's management with the goal of fraudulent reflection in accounting reporting.

\subsection{Problems arising during the practical application of the risk-oriented approach during audit proceedings.}

If applied effectively, the risk-oriented approach to audit proceedings helps to satisfy in full the requirements of the average informed user regarding accounting reporting, in particular by reducing informational risk in their decisions to a reasonable level. The basic characteristics of the risk-oriented approach, within the framework of which audit procedures are carried out with the aim of identifying the risk of considerable falsification of accounting reporting, are described in the documents published by IFAC (ISA 315, 2013; ISA 240, 2009; ISA 250, 2009). The listed professional standards are based on risk theory. In his article, Risk-based best audit practices in the Journal of Accountancy, Michael Ramos (2009) reflects upon some of the key issues in the widespread implementation of risk estimation standards. However, the use of risk theory as the basis for the risk-oriented approach assumes that tools are available that help to formulate a quantitative estimation of the risk that arises in the process of carrying out an audit assessment of the authenticity of accounting reporting. An overwhelming majority of audit companies, usually classified as small and medium-sized enterprises, do not have access to any acceptable methods of estimating the risk of considerable falsification of accounting reporting arising from fraudulent actions of the client's management. Hence, the development of new methods for estimating that risk is of paramount importance in enabling the practical application of the risk-oriented approach.

\subsection{Limitations of the model for estimating the risk of deliberate considerable falsification of reporting.}

The key aspect of estimating audit risk is the determination of the probability that the auditor may incorrectly estimate the authenticity of reporting under audit. Dr. Luc Quadackers (2002) provides a qualitative overview of the opportunities to assess risks with the help of probability methods in his book, Audit risk analysis: some statistical backgrounds. In particular, he describes the application of the Bayesian approach when estimating the audit risk component. Audit risk is made up of three main components, namely integral risk (internal risk/IR), risk connected with means of control (control risk/CR), and detection risk (DR), which, in turn, includes analytical errors (errors made when exercising control) and statistical errors (made when carrying out a selective check of operations). Multiplicative and additive models for estimating audit risk are widely applied in audit practice. The main limitation to this approach is that it simply cannot be applied when estimating the risk of considerable falsification of accounting reporting resulting from fraudulent actions of the management of the audited entity. IFAC audit standards only provide an approximate list of the factors that indicate the presence of said risk. It is clear that the difficulty of estimation lies in the need to take into consideration both quantitative and qualitative information. For this reason, the majority of methods applied to estimate audit risk are subdivided into ordinal (supposing that the auditor conducts a subjective estimation of qualitative information) and cardinal (quantitative). Moreover, most of these methods lead to the determination of the components of audit risk, not taking into account the risk of considerable falsification arising with regard to accounting reporting in general or during the course of its formulation.

The possibility of applying any particular method of risk estimation during audit proceedings should be determined, in our opinion, by the degree to which the following criteria are met:

A) Opportunity to identify and estimate all internal risks that become known to the auditor, and further determine those risks that, under certain circumstances, may lead to considerable or complete falsification of reporting.

B) An integral part of the procedure of estimating risk during audit proceedings is the use of audit judgment when determining which identified risks are considerable at the final stage of estimation. For this reason, the method applied must give the auditor the chance to use his/her own judgment to the level his/her professional competence allows.

C) The object of the audit, i.e. the accounting reporting, is at its core a database of the results of the company's activity. In order for the auditor to adequately interpret the essence of the company's results, the reporting 
must include both quantitative and qualitative information. Therefore, the method applied must enable the analysis of both quantitative and qualitative estimates made by the author of the accounting reporting and included therein.

D) The procedure for estimating risk during the audit process is cyclical in nature, based on the analysissynthesis method, widely applied in cognitive theory. In this regard, the applied method of risk analysis must help the auditor at the early stage to estimate the risks of considerable falsification contained within the reporting under audit, and subsequently perform graded disaggregation of these risks to their component factors. This disaggregation must allow the auditor to identify specific risk factors that are subject to quantitative change according to his/her professional judgment (analysis stage) and, subsequently, to carry out a complex estimation of the disaggregated factors (synthesis stage).

E) There is a logically predetermined interrelation, based on probability, between risks of considerable falsification identified during audit proceedings and the specific features of fraudulent actions at different levels. The applied method must take into account the fact that some of the identified risks of considerable falsification may be acknowledged as without value and, therefore, have no influence on the professional judgment of the auditor. On the other hand, when estimating the risk of fraudulent actions, it is important to take into consideration that this risk is much higher than that of inadvertent falsification of reporting arising from errors made during its preparation.

F) It is generally recognised that the system-oriented approach may be applied effectively to estimate all levels of the client's functioning internal control system (ICS), with the exception of the control environment. For this reason, the method applied to analysis should enable the assessment of risk at the level of the company's management, as well as risks arising due to the functioning of the usual control measures.

In addition, complex risk estimation requires that the applied approach facilitate integral risk estimation at different stages of the audit process. In particular, the primary level of risk should be estimated at the stage of estimation of the acceptability of relations with the client, potential risk should be estimated during the audit planning stage, actual risk should be estimated upon testing the ICS and audit procedures, and the final estimation should be made upon reaching the admissible risk level following corrective procedures.

\subsection{Conceptual approach to integral risk estimation during audit proceedings.}

The estimation of integral risk within an audit, in essence, formally presents a set of alternative solutions, requiring the auditor to select the most effective based on his/her analysis, and refers, as such, to the problem of making decisions under conditions of multi-criteria choice. One widely spread approach to making such decisions is the resultant of a vector test, taking into account weighted coefficients, determining the order of importance of and preference towards the various criteria with the goal of eliminating all but the single most important criteria. Another approach is to narrow the field of admissible solutions by introducing additional limitations. It is clearly necessary, when estimating risk within audit proceedings, to apply interactive methods of multi-criteria choice, the essence of which is a continuous approach to reaching a compromise by making amendments to the order of priority of criteria, their weighted coefficients, limitations and algorithms of solutions within the auditor's interaction with the computer on the basis of obtained data.

In resolving this task, additional difficulties arise in connection with the use of values measured in different scales and units, which demand the transformation of qualitative indexes into quantitative ones, and their transformation into a dimensionless form.

Taking into account all of the above, one may present a conceptual structure of the process of formulating an integral risk index within audit proceedings, as shown in Figure 1.

1. Solution generation: formation of a base of quantitative and qualitative indexes that characterise the object of the audit (i.e. accounting reporting). The following are basic methods of generating a solution: expert estimation, cognitive cards (which help to visualise the task via a graph reflecting the factors that characterise the risk).

2. Estimation of possible solutions in accordance with the auditor's preferences, and subsequent co-ordination of solutions: The main methods are "fuzzy numbers" and multi-criteria estimation (preference function method, preference ratio method, etc.).

3. Obtaining an integral solution (risk) and assessment of its conformity with the admissible risk level (logical and probabilistic method (e.g. Solozhentcev, 2004).

4. Staged cyclical analysis of the admissibility of assessed integral risk with the application of a computer data processing environment (repetition of stages 2 and 3 , and probably stage 1 ). 


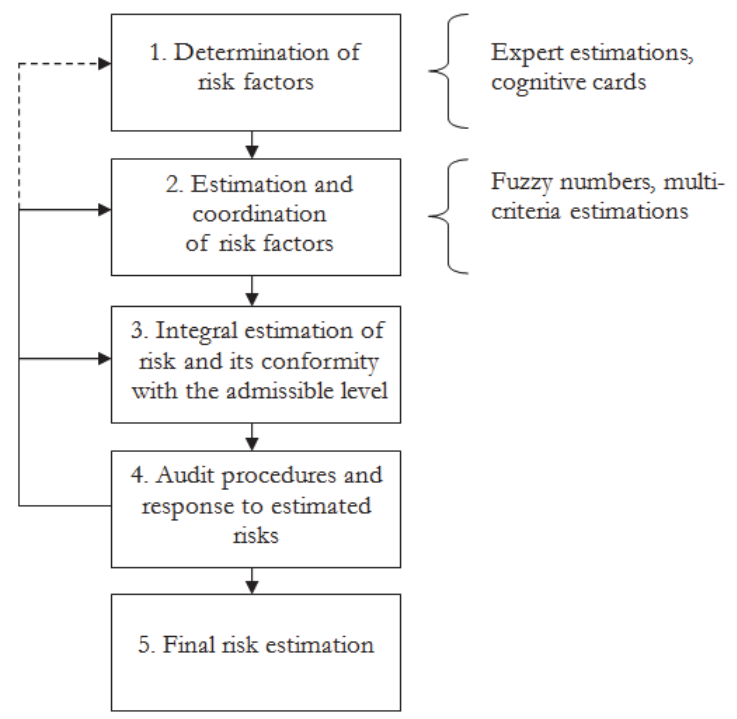

Figure 1. Structure of the conceptual approach to integral risk estimation within the audit process

The proposed approach makes it possible to estimate integral risk effectively within the audit process in accordance with the requirements above.

\section{Practical Example}

In our opinion, it is reasonable to structure the entire aggregate of risk factors in accordance with the basic postulate of fraud theory, widely known as the "fraud triangle". In this case, fraud is viable only when a motive can be determined. Therefore, the existence of a motive is the key condition for considering the possibility that fraud has been committed, provided there is a person who has a motive, is aware of an opportunity to commit fraudulent actions and has the ability to conceal those actions (ISA 240, 2009).

We propose presenting the factors forming the fraud triangle in the form of a matrix as demonstrated in the table below (Figure 2).

\begin{tabular}{|c|c|c|}
\hline Element of fraud triangle & Fraudulent formulation of reporting & Appropriation of assets \\
\hline Motive & 1 & 4 \\
\hline Known opportunity & 2 & 5 \\
\hline Means of concealing & 3 & 6 \\
\hline
\end{tabular}

Figure 2. Matrix model for structuring integral risk factors

Analysis is performed in regard to risk factors, grouped in accordance with the described algorithm, and presupposes that all members of the audit group with the right to make professional judgment will be involved. As an example, we will consider the way in which the risk of fraudulent actions is estimated based on the collective judgment of a group of $m$ auditors.

Each risk factor in a certain group (out the six groups specified in Figure 2 above) shall be measured applying the Likert scale. Let us assume that each of the $m$ auditors expresses his/her agreement or disagreement in regard to the judgment of each member of the group in accordance with the estimate scale.

Estimation in accordance with the Likert scale is expressed in terms of levels of agreement as follows (Elaine and Seaman, 2007):

(5) Completely agree; (4) Agree; (3) No opinion; (2) Disagree; (1) Completely disagree. 1 to 5 .

So, in relation to each factor within a certain group, we have judgments from each auditor, coded numerically from

Next, in order to transform the estimates from the Likert scale to an interval scale, we apply the Rasch (1980) model. Logit $d$ is the unit of the Rasch scale, and is calculated via the formula $d=\ln (P /(1-P))$, where $\mathrm{P}$ is probability of the 
choice of the particular risk factor. The higher the risk probability for a particular factor, the higher value it will receive in accordance with the Rasch scale.

For example, for the four Group 4 (Figure 2) motive factors toward asset appropriation, the group of six auditors provides the following primary data:

\begin{tabular}{|c|c|c|c|c|c|c|c|c|}
\hline Factor & $\mathrm{CD}(1)$ & $\mathrm{D}(2)$ & $\mathrm{N}(3)$ & $\mathrm{A}(4)$ & $\mathrm{CA}(5)$ & $S$ & $P$ & $d$ \\
\hline 1 & 1 & 2 & 1 & 1 & 1 & 17 & 0.57 & 0.27 \\
\hline 2 & 1 & 1 & 1 & 1 & 2 & 20 & 0.67 & 0.69 \\
\hline 3 & 1 & 2 & 2 & 1 & 0 & 15 & 0.50 & 0 \\
\hline 4 & 0 & 0 & 3 & 1 & 2 & 23 & 0.77 & 1.19 \\
\hline
\end{tabular}

As we see, one auditor completely disagrees, two auditors disagree, two auditors are neutral, one auditor agrees, and nobody completely agrees that "remuneration of managers with access to assets with a high degree of appropriation risk is reduced" (factor 3 in the table).

The algorithm of further actions for transforming this data into a quantitative scale is as follows: The value of the corresponding point, $S$, is calculated as the sum of the products of the number of auditors who opted for a particular level of agreement and the numerical value applied to that level. For example, for the fourth factor $S$ is calculated like so: $(0 \times 1)+(0 \times 2)+(3 \times 3)+(1 \times 4)+(2 \times 5)=23$. The maximal value for each factor is $6 \times 5=30$. Hence, the probability that the fourth factor will be selected is $23 / 30=0.77$. In accordance with the Rasch scale, the value of this factor is calculated as $d=\ln (P /(1-P))=1.19$. The same calculations are carried out for the remaining factors.

After obtaining quantitative estimation for each risk factor in the group, the integral risk index of the group is calculated as the sum of the estimates. The final risk estimation is the sum (simple or weighted) of the estimates for the six groups. In order to make this easier to interpret, it may be turned into an interval from 0 to 1 (based on the maximal value of risk).

\section{Conclusion}

In our opinion, the application of a formal methodological instrument will reap the following benefits: simplification of the procedure of collecting information concerning risks within the audit group before discussing the list of identified risk factors; reduced effort required to identify risks; increased audit efficiency, performed on the basis of the risk-oriented approach; coverage of all features confirming the risk of considerable falsification of accounting reporting; a greater level of preparedness among the audit group to discuss considerable falsification risk factors affecting accounting reporting undergoing audit proceedings.

\section{Summary}

The article proposes a method for estimating the risk of considerable falsification of accounting reporting as a result of fraudulent activity during its formulation. The proposed method meets the requirements of the informed users of the accounting reporting, including the main requirement, which is to decrease the informational risk inherent in their decisions to an admissible level.

\section{References}

Allen, Elaine and Seaman, Christopher (2007). Statistics Roundtable: Likert Scales and Data Analyses. Quality Progress, 40(7), 64-65. Dodge, R. (1990). Concise Guide to Auditing Standards and Guidelines, Chapman and Hall.

Finance director (2014). Corporate scandals. Retrieved May 31, 2014, from http://fd.ru/articles/38772-korporativnye-skandaly

ISA 315 (2013). Auditing identifying and assessing the risks of material misstatement through understanding the entity and its environment, IFAC.

ISA 240 (2009). The Auditor's Responsibilities Relating to Fraud in an Audit of Financial Statements, IFAC.

ISA 250 (2009). Consideration of laws and regulations in an Audit of Financial Statements, IFAC.

Ramos, M. (2009). Risk-Based-Audit-Best Practices. Journal of Accountancy, December. http://www.journalofaccountancy.com/ Issues/2009/Dec/20091789.htm

Rasch, G. (1980) Probabilistic models for some intelligence and attainment tests (revised and expanded ed.), The University of Chicago Press.

Roche-Duffay (2014). arefully, offshore! The biggest financial fraud and offshore scandals. Text available at: http://www.roche- 
duffay.ru/articles/beware.htm (accessed May 31, 2014)

Solozhentcev, E.D. (2004). Scenario Logic and Probabilistic Management of Risk in Business and Engineering, Publishing House "Business-press": Moscow.

Quadackers, L. (2002). Audit risk analysis: some statistical backgrounds. Manuscript, available at: http://www.finance-control.nl/ downloaden/6859/Audit-risk-analysis-some-statisical-backgrounds (accessed May 31, 2014). 